\title{
Characterization of Acid-Induced Protein Conformational Changes and Noncovalent Complexes in Solution by Using Coldspray Ionization Mass Spectrometry
}

\author{
Na Guo, ${ }^{a}$ Ruiping Zhang, ${ }^{\text {a }}$ Fei Song, ${ }^{\mathrm{b}}$ Jiuming $\mathrm{He}^{\text {a }}$ Bin Xia, \\ and Zeper Abliz ${ }^{\mathrm{a}}$ \\ ${ }^{a}$ Key Laboratory of Bioactive Substances and Resource Utilization of Chinese Herbal Medicine, Ministry of \\ Education, Institute of Materia Medica, Chinese Academy of Medical Sciences and Peking Union Medical \\ College, Beijing, China \\ ${ }^{\mathrm{b}}$ Beijing NMR Center, Peking University, Beijing, China
}

Coldspray ionization (CSI) mass spectrometry, a variant of electrospray ionization (ESI) operating at low temperature $\left(20\right.$ to $\left.-80^{\circ} \mathrm{C}\right)$, has been used to characterize protein conformation and noncovalent complexes. A comparison of CSI and ESI was presented for the investigation of the equilibrium acid-induced unfolding of cytochrome c, ubiquitin, myoglobin, and cyclophilin A (CypA) over a wide range of $\mathrm{pH}$ values in aqueous solutions. CSI and nanoelectrospray ionization (nanoESI) were also compared in their performance to characterize the conformational changes of cytochrome $\mathrm{c}$ and myoglobin. Significant differences were observed, with narrower charged-state distribution and a shift to lower charge state in the CSI mass spectra compared with those in ESI and nanoESI mass spectra. The results suggest that CSI is more prone to preserving folded protein conformations in solution than the ESI and nanoESI methods. Moreover, the CSI-MS data are comparable with those obtained by other established biophysical methods, which are generally acknowledged to be the suitable techniques for monitoring protein conformation in solution. Noncovalent complexes of holomyoglobin and the protein-ligand complex between CypA and cyclosporin A (CsA) were also investigated at a neutral $\mathrm{pH}$ using the CSI-MS method. The results of this study suggest the ability of CSI-MS in retaining of protein conformation and noncovalent interactions in solution and probing subtle protein conformational changes. Additionally, the CSI-MS method is capable of analyzing quantitatively equilibrium unfolding transitions of proteins. CSI-MS may become one of the promising techniques for investigating protein conformation and noncovalent protein-ligand interactions in solution. (J Am Soc Mass Spectrom 2009, 20, 845-851) (C) 2009 American Society for Mass Spectrometry

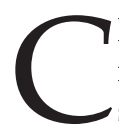
haracterization of native conformations and noncovalent complexes of proteins is of great significance to understanding a variety of biological processes at the molecular level. Electrospray ionization mass spectrometry (ESI-MS) [1,2] has grown into a powerful technique in this field. Besides its capability of handling large biomolecules, the advantages of ESI-MS over other spectroscopic and biophysical methods include high analysis speed, minimal sample consumption, and the characterization of individual conformational states that may coexist in solution at equilibrium [3-5]. The charge-state distribution (CSD) in the ESI mass spectra represents a specific conformational state of protein [6-9]. Broad CSDs at high charge states are generally associated with un-

Address reprint requests to Dr. Zeper Abliz, Chinese Academy of Medical Sciences and Peking Union Medical College, Institute of Materia Medica, 1 Xian Nong Tan Street, Beijing 100050 China. E-mail: zeper@imm.ac.cn folded proteins, whereas narrower distributions centered on lower charge states are treated as characteristics of folded proteins [6, 10-15]. However, the harsh conditions during the ionization process in MS are often detrimental to the preservation of protein conformation and the survival of noncovalent complexes. Many studies have examined the influence of the ionization process and the operating settings of ESI, including the curtain gas [16, 17], the pressure in the ion source [18-20], the temperature [21-26], the cone voltage [3, 27], the spray mode [28], and the solvent composition $[29,30]$. To preserve the native protein conformation, a significant amount of effort has also been made on modifications to the ESI source. The electrosonic spray ionization (ESSI) [31, 32] method, using a traditional micro ESI source with supersonic nebulizing gas, allows for the characterization of protein complexes in solution. In addition, the ESI source combined with an air amplifier (ESI-AA) [33] also showed improvement in 
preserving folded conformations. Nanospray [34-36] is often a gentle ionization method of allowing the use of less harsh conditions including a lower heated capillary temperature, the absence of heater gas, and a lower spray voltage while also providing high ionization efficiency for small-sample consumption. These advantages favor the application of nanospray to study protein conformation and noncovalent complexes [37-39].

Recently, coldspray ionization (CSI) mass spectrometry was developed. This method is a variant of ESI operating at low temperature $\left(20\right.$ to $\left.-80^{\circ} \mathrm{C}\right)$ and allows for the facile and precise characterization of labile organometallic complexes and organic and biomolecular noncovalent interactions in solution [40-47]. In the present study, the equilibrium acid-induced conformational transitions of proteins, including cytochrome c, ubiquitin, myoglobin, and cyclophilin A (CypA), were investigated using CSI-TOFMS, a coldspray ion source combined with a time-of-flight (TOF) mass analyzer, over a wide range of $\mathrm{pH}$ values in aqueous solutions. Furthermore, noncovalent complexes were observed in the case of holomyoglobin (the heme group is noncovalently bound in a hydrophobic pocket of myoglobin [48]) and the protein-ligand complex between CypA and cyclosporin A (CsA). CypA is a ubiquitously distributed intracellular protein belonging to the immunophilin family and is recognized as the host cell receptor for the potent immunosuppressive drug CsA [49-51]. Compared with conventional ESI and nanoESI, CSI has clear advantages in investigating acid-induced conformational transitions and protein-ligand complexes. In this study, we demonstrated for the first time that the CSI-MS method has the capacity of characterizing protein conformations and protein complex structures in solution.

\section{Experimental}

\section{Materials and Sample Preparation}

Ubiquitin, cytochrome c, and horse heart myoglobin were purchased from Sigma-Aldrich (St. Louis, MO, USA). The sample solutions were prepared by dissolving the proteins in water to a concentration of $5 \mathrm{mg}$ $\mathrm{mL}^{-1}$ and then diluting to $1 \mu \mathrm{mol} \mathrm{L}{ }^{-1}$ using aqueous ammonium hydroxide or acetic acid. The $\mathrm{pH}$ of the solution was adjusted by adding acetic acid or ammonium hydroxide and was measured with an Accumet meter (AB 15, Fisher Scientific, Pittsburgh, PA, USA) before the addition of protein. The DNA fragment encoding human CypA was cloned into the pET32a vector (Novagen, San Diego, CA, USA) with NdeI/ Hind III restriction enzymes and CypA was expressed as a fusion protein with a C-terminal histidine tag. The fusion proteins were affinity-purified with a Ni-NTA Agarose column (Invitrogen, Carlsbad, CA, USA) according to standard methods. CsA was purchased from Ruibio (Darmstadt, Germany).

\section{Mass Spectrometry}

The CSI/ESI-TOF mass spectra were acquired using an AccuTOF CS mass spectrometer (JMS-T100CS, JEOL, Tokyo, Japan). The needle voltage was set at $2.2-2.4 \mathrm{kV}$; the orifice 1 voltage was set at $40 \mathrm{~V}$ and the orifice 2 voltage was set at $6 \mathrm{~V}$. The flow rate of nebulizer gas was set at 1.0 to $2.0 \mathrm{~L} / \mathrm{min}$. The spray temperature was set between -20 and $20^{\circ} \mathrm{C}$ for CSI measurements, whereas the desolvation chamber temperature was set between 200 and $250{ }^{\circ} \mathrm{C}$ for conventional ESI measurements.

The positive-ion nanoelectrospray ionization experiments were performed using an Applied Biosystems QSTAR Elite system, equipped with a nanoelectrospray ion source (Concord, ON, Canada). The MS conditions were as follows: curtain gas, 20 (arbitrary units); ionspray voltage, $1900 \mathrm{~V}$; nebulizer gas, 23 (arbitrary units); declustering potential, $40 \mathrm{~V}$; heater gas (gas 2) and interface heater temperature, no use.

\section{Results and Discussion}

To obtain optimal operating conditions for the characterization of folded protein conformations in solution, the investigation of the effect of spray temperature on the ESI and CSI mass spectra of the model protein, cytochrome c, was carried out at $\mathrm{pH} 2.5$. All other instrumental parameters were also optimized. In addition, a nanoESI mass spectrum was obtained under the same solution conditions. It was anticipated that a bimodal CSD would be present in the mass spectra corresponding to the coexistence of the folded and unfolded states of cytochrome $\mathrm{c}$ at $\mathrm{pH} 2.5[52,53]$. The mass spectra obtained at varying temperatures are shown in Figure 1 and Supplementary Figure S1, which can be found in the electronic version of this article. As illustrated in Figure $1 \mathrm{a}$, in the ESI mass spectrum obtained at $250{ }^{\circ} \mathrm{C}$ only a single-mode CSD centered at +16 , corresponding to the unfolded protein, was observed. As the temperature was decreased, Figure $1 \mathrm{~b}-\mathrm{e}$ clearly demonstrate that in addition to the high charge-state distribution, another distribution centered at +8 corresponding to the folded protein can be observed. These results illustrate that a relatively high abundance of the folded form can be obtained using CSI-MS at spray temperatures ranging from 20 to $-20^{\circ} \mathrm{C}$. A single-mode CSD centered at +16 corresponding to the unfolded protein was observed in the nanoESI mass spectrum (Figure 1f) similar to the one observed in a conventional ESI mass spectrum. The advantage observed with nanoESI was an increase in sensitivity compared with that of conventional ESI. However, there were evident differences between the nanoESI mass spectrum (Figure 1f) and the CSI mass spectrum (Figure 1c) obtained at almost the same temperature, which can be traced to the different acid-induced effects associated with the differences in designs of ion source and ionization processes. The conformational transition of cytochrome $\mathrm{c}$ is very sensitive to the change of $\mathrm{pH}$ value around 2.5 [53]; the 
variation in $\mathrm{pH}$ values of the droplets under nanoESI ionization conditions probably cause evident acid-induced denaturation. These results suggest that CSI is more suited to the preservation of solution-phase conformations than either the ESI or nanoESI methods. It is noted that the relative amount of folded cytochrome c characterized using CSI-MS at $10^{\circ} \mathrm{C}$ is consistent with that obtained by spectroscopic techniques [52]. Thus, a spray temperature of $10^{\circ} \mathrm{C}$ was adopted in this study.

For purposes of comparison, CSI and ESI mass spectra were collected using cytochrome $\mathrm{c}$ at solution $\mathrm{pH}$ values ranging from 11.0 to 3.0. Among these spectra, those collected at $\mathrm{pH}$ values of 3.0, 7.0, and 11.0 are shown in Figure 2 and those collected at $\mathrm{pH}$ values of 5.2 are shown in Supplementary Figure S2. As shown in Figure 2a-c and Supplementary Figure S2a, singlemode and narrow CSDs with maximum at +7 or +8 were recorded for cytochrome $\mathrm{c}$ in CSI mass spectra obtained at $\mathrm{pH}$ values between 11.0 and 3.0, indicating a tightly folded conformation. In the ESI mass spectra (Figure $2 \mathrm{~d}-\mathrm{f}$ and Supplementary Figure S2b), broadening CSDs associated with an unfolded protein were observed in this $\mathrm{pH}$ range. Along with further acidification of the solution, the distribution and the maximum charge state are gradually shifted to higher charge states and extend up to +16 at $\mathrm{pH} 3.0$ in the ESI mass spectra.

In addition, the cooperative effects of $\mathrm{pH}$ and temperature on the unfolding of cytochrome $\mathrm{c}$ were inves-
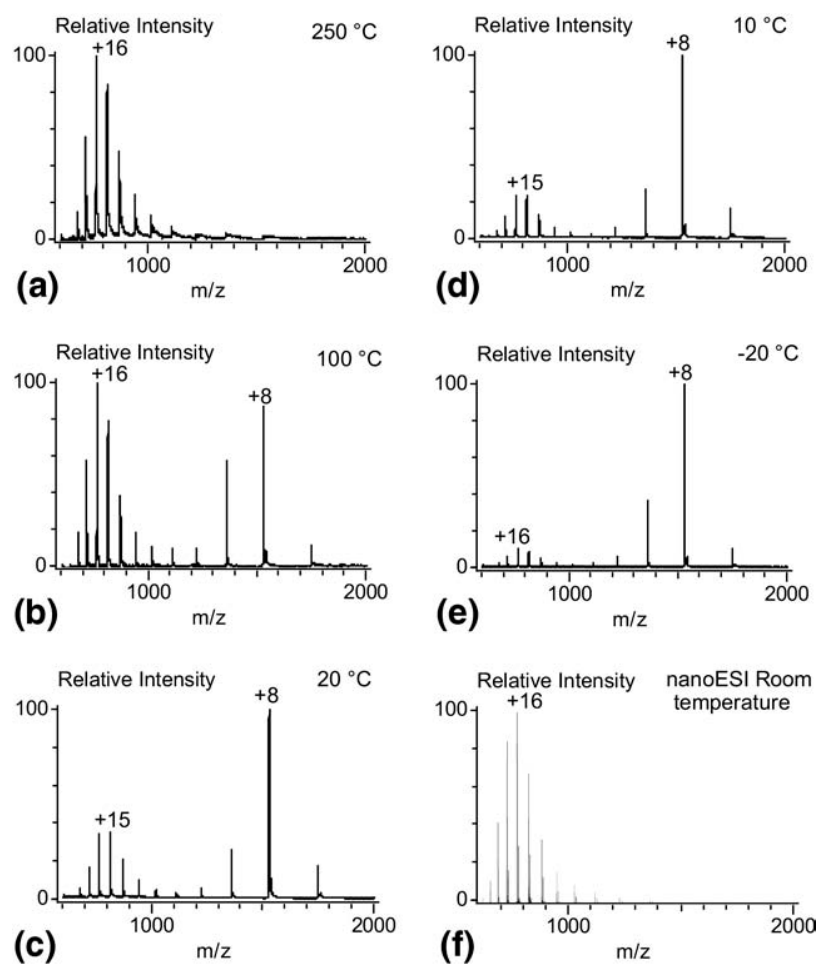

Figure 1. ESI (a, conventional temperature of ESI-MS, b, different temperature of ESI-MS), CSI (c-e) and nanoESI (f, room temperature) mass spectra of cytochrome $\mathrm{c}$ in water and acetic acid ( $\mathrm{pH} 2.5)$.
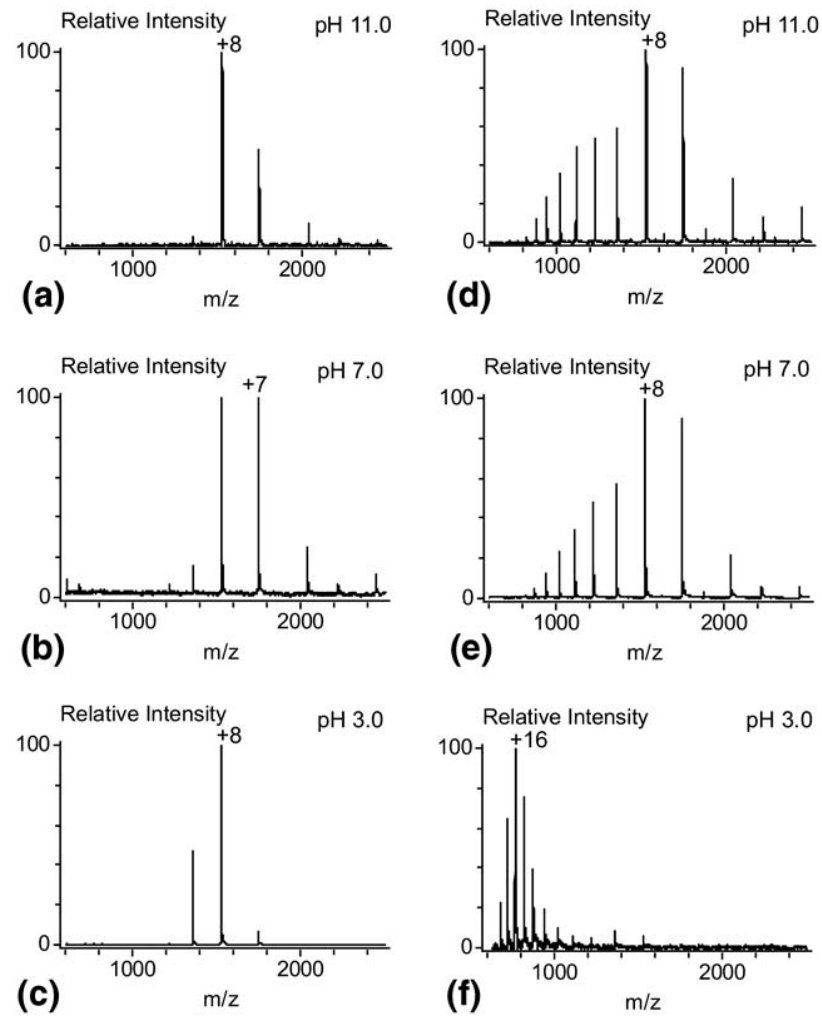

Figure 2. CSI ( $\mathbf{a}, \mathbf{b}$, and $\mathbf{c})$ and ESI (d, e, and $\mathbf{f})$ mass spectra for cytochrome $\mathrm{c}$ at $\mathrm{pH}$ 11.0, 7.0, and 3.0.

tigated. The tightly folded conformation relative to the total in both tightly and loosely folded conformations is plotted against temperature for $\mathrm{pH}$ values of 5.2, 3.4, and 3.0 in Figure 3a. The fraction of folded protein for cytochrome $\mathrm{c}$ was calculated as the sum of intensities of the peaks corresponding to the $+6,+7,+8,+9$, and +10 ions, divided by the sum over all the peaks.

Folded $\%=\frac{\sum_{i=6-10} I i}{\sum_{i=1-n} I i}$

As can be seen from Figure 3a, the results obtained at the temperature of CSI reflect the folded state of cyto-
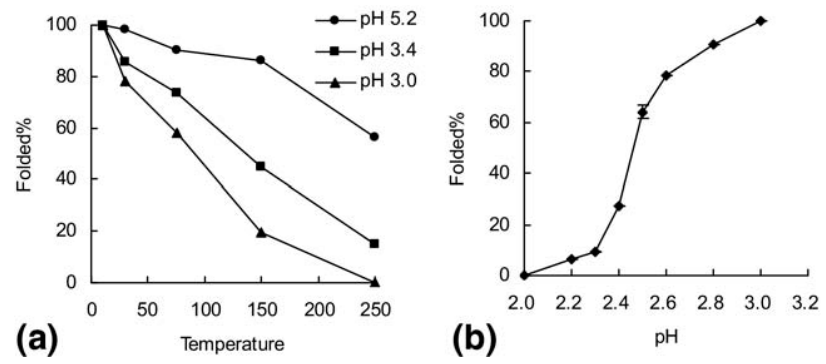

Figure 3. (a) Relative amounts of folded cytochrome c versus temperature at three different values of solution $\mathrm{pH}$ using CSI/ ESI-MS detection. (b) Relative amounts of folded cytochrome c against $\mathrm{pH}$ values using CSI-MS. The error bars for CSI-MS data represent the standard deviation. 
chrome $\mathrm{c}$ in solution. Under the same temperature, the lower the $\mathrm{pH}$, the more difficult it is to maintain a folded conformation, which demonstrates that the actual $\mathrm{pH}$ values of the droplets are much lower than those of the native solution under ESI ionization conditions [54, 55], and thus result in additional acid-induced unfolding. Under the same $\mathrm{pH}$, the higher the temperature, the more difficult it is to maintain a folded conformation because of heat-induced unfolding. These results reveal that the $\mathrm{pH}$ and temperature cooperatively influence the ESI ionization process and thus induce alterations to the CSD. Moreover, we used CSI-MS to quantitatively analyze the equilibrium of the unfolding transitions. Figure $3 b$ shows the relative amount of folded cytochrome $\mathrm{c}$ in CSI mass spectra at solution $\mathrm{pH}$ values from 2.0 to 3.0 according to eq 1 . As illustrated in Figure $3 b$, the relative amount of the folded form obtained by CSI-MS matches the values obtained using tryptophan fluorescence spectrometry [52]. These results indicate that the CSI-MS method preserves the native protein structure, especially under low $\mathrm{pH}$ values, and has the advantage of being able to accurately characterize acid-induced equilibrium unfolding transitions.

Series of spectra for ubiquitin were also obtained for solution $\mathrm{pH}$ values ranging from 11.0 to 1.2 by using ESI-MS and CSI-MS. Among these spectra, those collected at $\mathrm{pH}$ values of $7.0,2.3$, and 1.7 are shown in Figure 4 and those collected at $\mathrm{pH}$ values of 2.0 and 1.2 are shown in Supplementary Figure S3. Single-mode
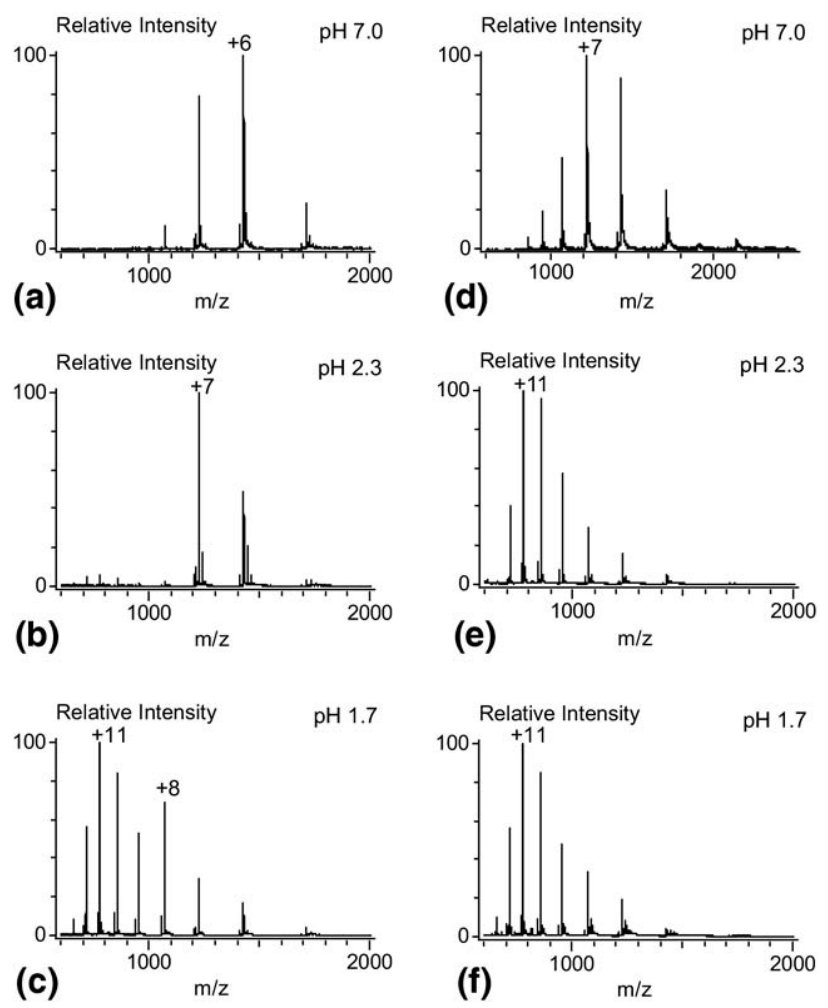

Figure 4. CSI $(\mathbf{a}, \mathbf{b}, \mathbf{c})$ and ESI $(\mathbf{d}, \mathbf{e}, \mathbf{f})$ mass spectra for ubiquitin at $\mathrm{pH} 7.0,2.3$, and 1.7.
CSDs centered at +6 or +7 charge states corresponding to the folded ubiquitin were observed for solution $\mathrm{pH}$ values 7.0 to 2.3 in CSI-MS spectra (Figure $4 a$ and b). No pronounced changes of the CSD in CSI mass spectra between $\mathrm{pH} 11.0$ and 2.3 were observed (some of the data are not shown), which are in accordance with the results of a previous study performed by CD spectroscopy [56]. Below pH 2.3, another distribution centered at +11 appeared in the CSI mass spectra (Supplementary Figure S3a). Notably, a new distribution with main peaks at +8 and +9 was observed when the $\mathrm{pH}$ values decrease to 1.7 (Figure 4c), indicating the presence of an acid-induced unfolded ubiquitin intermediate $[22,57,58]$. Figure $4 \mathrm{~d}$ shows that the maximum at $\mathrm{pH} 7.0$ in the ESI mass spectrum remains at +7 but the charge-state distribution is broadened. A further decrease in the solution $\mathrm{pH}$ values results in the distribution and the maximum charge state to be gradually shifted to higher values (Figure 4e and f and Supplementary Figure S3c). As shown in Supplementary Figure S3b and d, the high charge states completely dominate the spectra at $\mathrm{pH} 1.2$, and the results of CSI-MS and ESI-MS spectra are almost the same. The above-cited results further emphasize that the prevention of thermal-induced and additional acid-induced effects during the CSI process enables the CSI method to be used for precisely monitoring conformational changes.

An analogous set of experiments was performed for horse heart myoglobin at $\mathrm{pH}$ values ranging from 11.0 to 2.2 by using CSI-MS, ESI-MS, and nanoESI-MS. The spectra obtained at $\mathrm{pH} 7.6,4.0$, and 3.4 are shown in Figure 5. In the CSI mass spectra, the intact folded holomyoglobin $(\mathrm{hMb})$ was observed at $\mathrm{pH} 7.6$ (Figure $5 \mathrm{a}), \mathrm{pH} 4.0$ (Figure 5b), and above (data not shown). Figure $5 \mathrm{~d}$ shows that $\mathrm{hMb}$ and $\mathrm{aMb}$ ions in higher and lower charge states were observed in the ESI mass spectra. The dominant peaks in the ESI mass spectrum (Figure 5e) at $\mathrm{pH} 4.0$ are attributed to $\mathrm{aMb}$ in high charge states. Supplementary Figure S4a shows that the intact folded $\mathrm{hMb}$ was obtained at $\mathrm{pH} 7.6$ in the nanoESI spectrum. In the nanoESI mass spectrum (Supplementary Figure S4b) distributions of $\mathrm{hMb}$ ions with main peaks at +10 were observed and $\mathrm{aMb}$ ions in higher charge states $(+16)$ appear with low intensity when $\mathrm{pH}$ values decrease to 4.0. Furthermore, as can be seen from Figure $5 \mathrm{~g}$ obtained at $\mathrm{pH} 3.4$ (a magnified portion of Figure $5 \mathrm{c}$ ), in addition to the high CSD associated with the unfolded $\mathrm{aMb}$, the magnified CSI mass spectrum exhibits a bimodal distribution of $\mathrm{hMb}$ with one distribution with a maximum at $10+$ and a second maximum around 14+. Previous studies [5961] showed that the kinetics of $\mathrm{hMb}$ unfolding under acidic conditions follow a two-step mechanism. In the first step a short-lived intermediate that is unfolded becomes populated, but still retains its heme group. In the second step the unfolded heme-protein dissociates and unfolded $\mathrm{aMb}$ and free heme are formed. The coexistence of three CSDs corresponding to folded $\mathrm{hMb}$, unfolded $\mathrm{hMb}$, and unfolded $\mathrm{aMb}$ in the CSI mass 

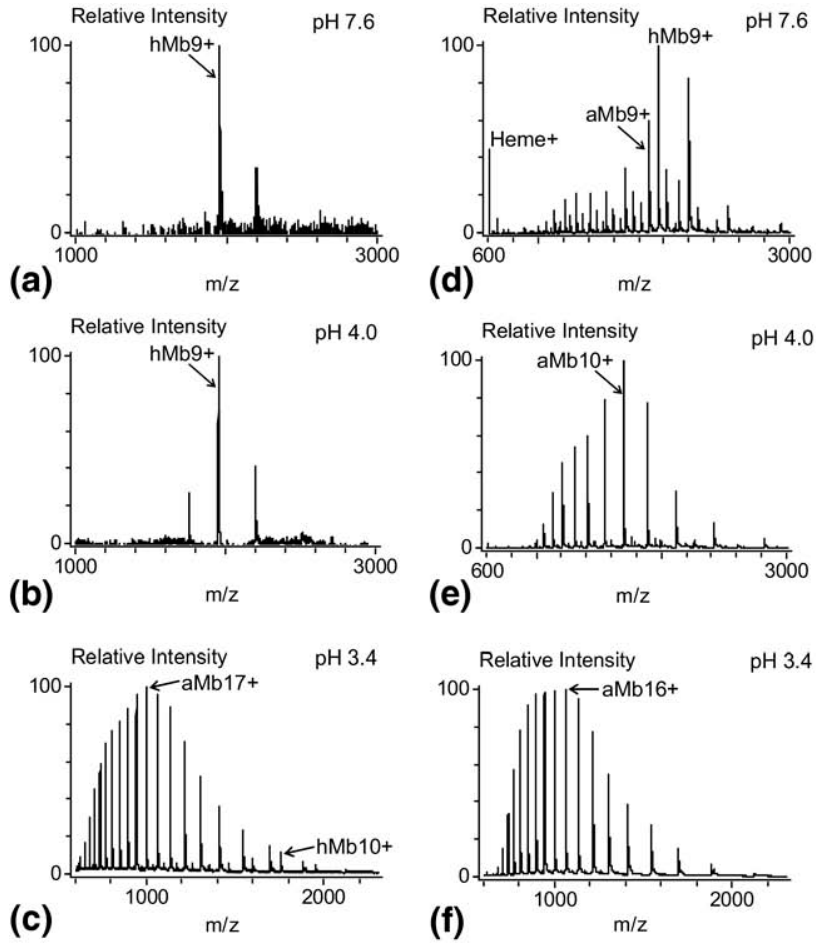

(e)

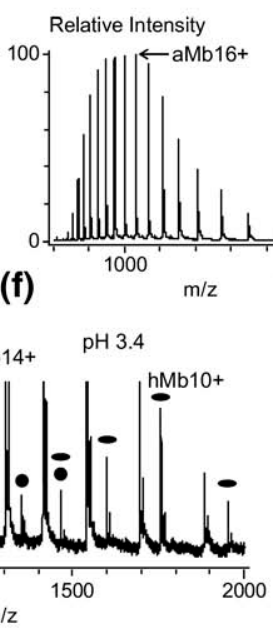

(g)

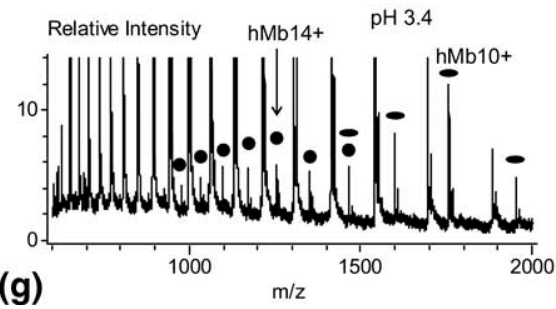

Figure 5. CSI $(\mathbf{a}, \mathbf{b}, \mathbf{c})$ and ESI $(\mathbf{d}, \mathbf{e}, \mathbf{f})$ mass spectra for myoglobin at $\mathrm{pH}$ 7.6, 4.0, and 3.4. (g) A magnified CSI mass spectrum at $\mathrm{pH}$ 3.4. Biomodal CSDs of hMb with maximum at hMb10+ corresponding to the folded myoglobin (labeled by ellipse) and $\mathrm{hMb} 14+$ identified with the folded intermediate (labeled by ball).

spectrum provides evidence for the kinetics of $\mathrm{hMb}$ unfolding. Moreover, the $\mathrm{pH}$ value of 3.4, the lowest at which $\mathrm{hMb}$ peaks were observed in equilibrium with CSI-MS, is lower than values reported using ESI-MS, even when gentle conditions were used [33]. The ESI (Figure 5f) and nanoESI (Supplementary Figure S4c) mass spectra show the distributions of $\mathrm{aMb}$ in higher charge states corresponding to unfolded proteins. The above-cited results clearly demonstrate the ability of the CSI-MS method to preserve native protein conformation, noncovalent complex structures and its ability to monitor the transient unfolding of intermediates.

Based on the preceding investigations, the proteinligand complex between CypA and CsA was further studied by using the CSI-MS method. The conformational transitions of CypA were observed by CSI-MS and ESI-MS at solution $\mathrm{pH}$ values ranging from 11 to 3.2. Once again, significant differences between CSI and ESI mass spectra were obtained. Figure $6 a$ and $b$ show that the folded conformation of CypA was retained in the CSI mass spectra from $\mathrm{pH} 7.0$ to 4.3. No significant changes in the CSI mass spectra were found between $\mathrm{pH}$ values 11.0 to 4.3 (some data are not shown). Below pH 4.0 another distribution centered at +19 appeared (see Supplementary Figure S5a). When the solution $\mathrm{pH}$ value was decreased to 3.2 the high charge states completely dominated the spectra (Supplementary Figure S5b). The single-mode distributions in the ESI mass spectra (Figure 6d and Supplementary Figure S5c and d) under the same $\mathrm{pH}$ range are interpreted as representing unfolded proteins, whereas the bimodal distribution (Figure 6c) indicates the coexistence of folded and unfolded protein. It is worth noting that intact CypA-CsA noncovalent complex ions can be observed in the CSI mass spectrum under nearly physiological conditions ( $\mathrm{pH}$ 7.0). Figure 6e shows that native CypA interacted selectively with CsA at $+8,+9$, and +10 charged states. However, the intact folded CypA-CsA complex ion was absent in the ESI mass spectrum (Figure 6f). These results suggest that the CSI-MS method can provide specific binding information for the CypA-CsA complex and can be used to search for ligand candidates with a specific affinity for a target protein.

The results reported in this study demonstrate the advantage of the CSI-MS method in characterizing
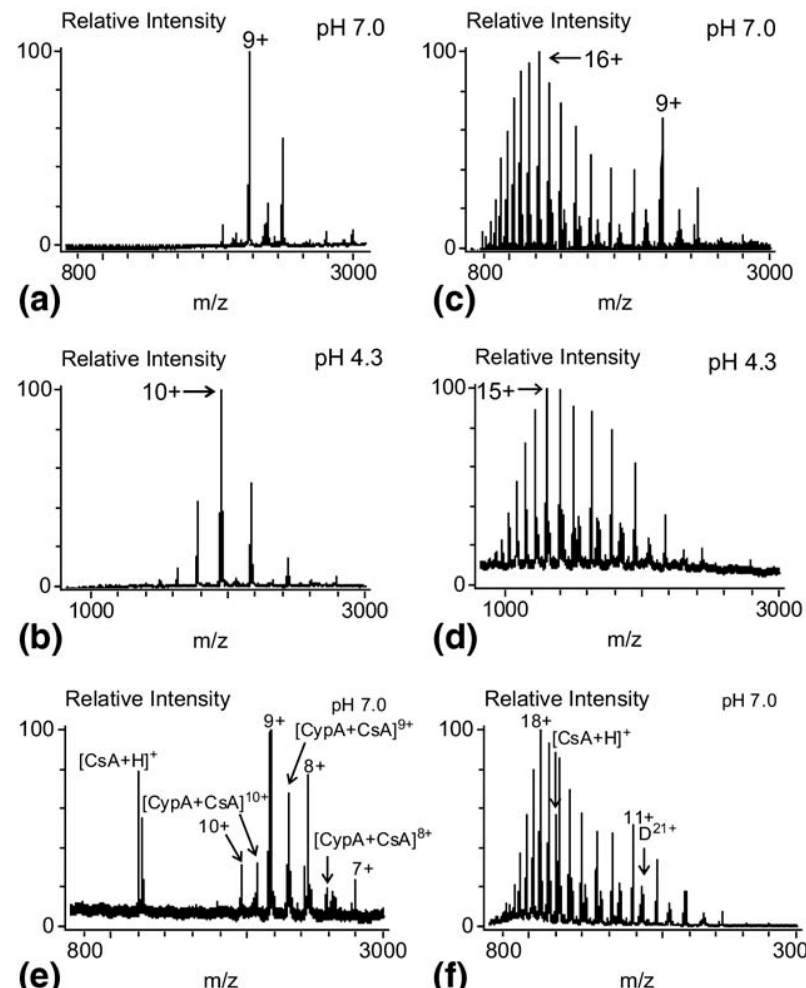

(d)

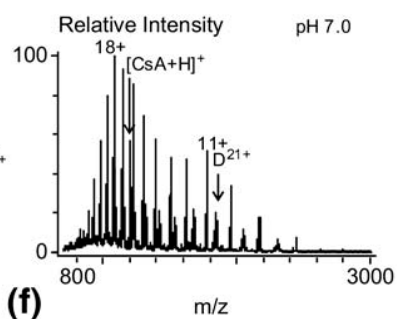

Figure 6. CSI $(\mathbf{a}, \mathbf{b})$ and ESI $(\mathbf{c}, \mathbf{d})$ mass spectra for CypA at $\mathrm{pH}$ 7.0 and 4.3. CSI (e) and ESI mass spectrum (f) of CypA in a mixture with CsA at pH 7.0 (1:1 molecular ratio at concentration level of $100 \mu \mathrm{M}) .8+, 9+$, and $10+$ indicate $[\mathrm{MCypA}+2 \mathrm{H}+6 \mathrm{Na}]^{8+}$, $[\mathrm{MCypA}+3 \mathrm{H}+6 \mathrm{Na}]^{9+}$, and $[\mathrm{MCypA}+4 \mathrm{H}+6 \mathrm{Na}]^{10+}$, respectively; $\mathrm{D}^{21+}$ indicates $[2 \mathrm{MCypA}+21 \mathrm{H}]^{21+}$. 
native protein conformation and noncovalent complexes. Notably, CSI ionization has the capability of preventing heat-induced denaturation and acid-induced conformational transitions at low $\mathrm{pH}$ values. On the basis of the fact that CSI enables the precise characterization of labile organic species and noncovalent interactions of biomolecules in solution and affords multiply charged molecular ions attached with multiple solvent molecules, it is believed that CSI possesses an unusual ionization mechanism [42, 43]. It is supposed that in addition to providing gentle ionization conditions the CSI ionization process results in the formation of droplets that form cluster ions similarly to an aerosol and that this, in turn, preserves the solution structures.

\section{Conclusions}

We compared the performance of CSI, ESI, and nanoESI for characterization of acid-induced protein conformational changes and noncovalent complexes. The results demonstrated that the CSI technique is not merely a low-temperature ESI because it uses a unique process of ion formation and ion transformation. CSI has clear advantages over conventional ESI and nanoESI in the characterization of acid-induced conformational transitions. The noncovalent complexes of holomyoglobin and the protein-ligand complex between CypA and CsA were also characterized using CSI-MS at a neutral $\mathrm{pH}$. The CSI-MS data are in good agreement with solution phase results from the literature. We found that the CSI method is a reliable and facile analytical method that can directly characterize different conformational states for proteins, which are not easily separated by spectroscopic and biophysical methods. CSI-MS may become one of the promising techniques for investigating native protein conformation and noncovalent protein-ligand interactions.

\section{Acknowledgments}

Financial support from the New Analysis Technology and Method Research Program of the Chinese Ministry of Science and Technology (Grant No.2005JG200050) is gratefully acknowledged.

\section{Appendix A. Supplementary Material}

Supplementary material associated with this article may be found in the online version at doi:10.1016/ j.jasms.2008.12.024.

\section{References}

1. Fenn, J. B.; Mann, M.; Meng, C. K.; Wong, S. F.; Whitehouse, C. M. Electrospray Ionization for Mass Spectrometry of Large Biomolecules. Science 1989, 246, 64-70.

2. Fenn, J. B. Electraspray Wings for Molecular Elephants. Angew. Chem. Int. Ed. 2003, 42, 3871-3894.

3. Winston, R. L; Fitzgerald, M. C. Mass Spectrometry as a Readout of Protein Structure and Function. Mass Spectrom. Rev. 1997, 16, 165-179.

4. Grandori, R. Electrospray Ionization Mass Spectrometry for Protein Conformational Studies. Curr. Org. Chem. 2003, 7, 1589-1603.
5. Eyles, S. J; Kaltashov, I. A. Methods to Study Protein Dynamics and Folding by Mass Spectrometry. Methods 2004, 34, 88-99.

6. Konermann, L. A Minimalist Model for Exploring Conformational Effects on the Electrospray Charge State Distribution of Proteins. J. Phys. Chem. B 2007, 111, 6534-6543.

7. Peschke, M.; Blades, A.; Kebarle, P. Charged States of Protein Reactions of Doubly Protonated Alkyldiamines with $\mathrm{NH}_{3}$ : Solvation or Deprotonation Extension of Two Proton Cases to Multiply Protonated Globular Proteins Observed in the Gas Phase. J. Am. Chem. Soc. 2002, 124, 11519-11530.

8. Vekerk, U. H.; Peschke, M.; Kebarle, P. Effect of Buffer Cations and of $\mathrm{H}_{3} \mathrm{O}^{+}$on the Charge States of Native Proteins: Significance to Determinations of Stability Constants of Protein Complexes. J. Mass Spectrom. 2003, 38, 618-631.

9. Wang, G.; Cole, R. B. Mechanistic Interpretation of the Dependence of Charge State Distributions on Analyte Concentrations in Electrospray Ionization Mass Spectrometry. Anal. Chem. 1995, 67, 2892-2900.

10. Chowdhury, S. K.; Katta, V.; Chait, B. T. Probing Conformational Changes in Proteins by Mass Spectrometry. J. Am. Chem. Soc. 1990, 112, 9012-9013.

11. Loo, J. A.; Edmonds, C. G.; Udseth, H. R.; Smith, R. D. Effect of Reducing Disulfide-Containing Proteins on Electrospray Ionization Mass Spectra. Anal. Chem. 1990, 62, 693-698.

12. Kaltashov, I. A.; Eyles, S. Studies of Biomolecular Conformations and Conformational Dynamics with Mass Spectrometry. Mass Spectrom. Rev. 2002, 21, 37-71.

13. Mohimen, A.; Dobo, A.; Hoerner, J. K.; Kaltashov, I. A. A Chemometric Approach to Detection and Characterization of Multiple Protein Conformers in Solution Using Electrospray Ionization Mass Spectrometry. Anal. Chem. 2003, 75, 4139-4147.

14. Navea, S.; Tauler, R.; de Juan, A. Monitoring and Modeling of Protein Processes Using Mass Spectrometry, Circular Dichroism, and Multivariate Curve Resolution Methods. Anal. Chem. 2006, 78, 4768-4778.

15. Kuprowski, M. C.; Konermann, L. Signal Response of Coexisting Protein Conformers in Electrospray Mass Spectrometry. Anal. Chem. 2007, 79, 2499-2506.

16. Konishi, Y.; Feng, R. Conformational Stability of Heme Proteins In Vacuo. Biochemistry 1994, 33, 9706-9711.

17. Šamalikova, M.; Matečko, I.; Müller, N. Interpreting Conformational Effects in Protein Nano-ESI-MS Spectra. Anal. Bioanal. Chem. 2004, 378, 1112-1123.

18. Schmidt, A.; Bahr, U.; Karas, M. Influence of Pressure in the First Pumping Stage on Analyte Desolvation and Fragmentation in Nano-ESIMS. Anal. Chem. 2001, 73, 6040-6046.

19. Tahallah, N.; Pinkse, M.; Maier, C. S.; Heck, A. J. R. The Effect of the Source Pressure on the Abundance of Ions of Noncovalent Protein Assemblies in an Electrospray Ionization Orthogonal Time-of-Flight Instrument. Rapid Commun. Mass Spectrom. 2001, 15, 596-601.

20. Heck, A. J. R.; van den Heuvel, R. H. H. Investigation of Intact Protein Complexes by Mass Spectrometry. Mass Spectrom. Rev. 2004, 23, 368 389.

21. Mirza, U. A.; Cohen, S. L.; Chait, B. T. Heat-Induced Conformationa Changes in Proteins Studied by Electrospray Ionization Mass Spectrometry. Anal. Chem. 1993, 65, 1-6.

22. Mirza, U. A.; Chait, B. T. Do Proteins Denature During Droplet Evolution in Electrospray Ionization? Int. J. Mass Spectrom. Ion Process. 1997, 162, 173-181.

23. Fligge, T. A.; Przybylski, M.; Quinn, J. P.; Marshall, A. G. Evaluation of Heat-Induced Conformational Changes in Proteins by Nanoelectrospray Fourier Transform ion Cyclotron Resonance Mass Spectrometry. Eur. J. Mass Spectrom. 1998, 4, 401-404.

24. Li, J.; Taraszka, J. A.; Counterman, A. E.; Clemmer, D. E. Influence of Solvent Composition and Capillary Temperature on the Conformations of Electrosprayed Ions: Unfolding of Compact Ubiquitin Conformers from Pseudonative and Denatured Solutions. Int. J. Mass Spectrom. 1999, 185/186/187, 37-47.

25. Grandori, R.; Matecko, I.; Mayr, P.; Müller, N. Probing Protein Stabilization by Glycerol Using Electrospray Mass Spectrometry. J. Mass Spectrom. 2001, 36, 918-922.

26. Schmidt, A.; Karas, M. The Influence of Electrostatic Interactions on the Detection of Heme-Globin Complexes in ESI-MS. I Am. Soc. Mass Spectrom. 2001, 12, 1092-1098.

27. Meunier, C.; Jamin, M.; De Pauw, E. On the Origin of the Abundance Distribution of Apomyoglobin Multiply Charged Ions in Electrospray Mass Spectrometry. Rapid Commun. Mass Spectrom. 1998, 12, 239-245.

28. Nemes, P.; Marginean, I.; Vertes, A. Spraying Mode Effect on Droplet Formation and Ion Chemistry in Electrosprays. Anal. Chem. 2007, 79, 3105-3116.

29. Iavarone, A. T.; Williams, E. R. Mechanism of Charging and Supercharging Molecules in Electrospray Ionization. J. Am. Chem. Soc. 2003, 125, 2319-2327.

30. Šamalikova, M.; Grandori, R. Protein Charge-State Distributions in Electrospray-Ionization Mass Spectrometry Do Not Appear To Be Limited by the Surface Tension of the Solvent. J. Am. Chem. Soc. 2003, 125, 13352-13353.

31. Takáts, Z.; Wiseman, J.; Gologan, M. B.; Cooks, R. G. A Gentle Technique for Generating Folded Proteins and Protein Complexes in the Gas Phase and Studying Ion-Molecule Reactions at Atmospheric Pressure. Anal. Chem. 2004, 76, 4050-4058. 
32. Wiseman, J. M.; Takáts, Z.; Gologan, B.; Davisson, V. J.; Cooks, R. G. Direct Characterization of Enzyme-Substrate Complexes by Using Electrosonic Spray Ionization Mass Spectrometry. Angew. Chem. Int. Ed. 2005, 44, 913-916.

33. Yang, P.; Cooks, R. G.; Ouyang, Z. Gentle Protein Ionization Assisted by High-Velocity Gas Flow. Anal. Chem. 2005, 77, 6174-6183.

34. Wilm, M. S.; Mann, M. Electrospray and Taylor-Cone Theory, Dole's Beam of Macromolecules at Last. Int. J. Mass Spectrom. Ion Process. 1994, 136, 167-180.

35. Wilm, M. S.; Mann, M. Analytical Properties of the Nanoelectrospray Ion Source. Anal. Chem. 1996, 68, 1-8.

36. Wilm, M. S.; Shevchenko, A.; Houthaeva, T.; Breit, S.; Schweigerer, L.; Fotsis, T.; Mann, M. Femtomole Sequencing Proteins from Polyacrylamide Gels by Nano-Electrospray Mass Spectrometry. Nature 1996, 379, $466-469$.

37. Sun, J.; Kitova, E. N.; Wang, W.; Klassen, J. S. Method for Distinguishing Specific from Nonspecific Protein-Ligand Complexes in Nanoelectrospray Ionization Mass Spectrometry. Anal. Chem. 2006, 78, 3010-3018.

38. Sun, J.; Kitova, E. N.; Klassen, J. S. Method for Stabilizing ProteinLigand Complexes in Nanoelectrospray Ionization Mass Spectrometry. Anal. Chem. 2007, 79, 416-425.

39. Sun, J.; Kitova, E. N.; Sun, N.; Klassen, J. S. Method for Identifying Nonspecific Protein-Protein Interactions in Nanoelectrospray Ionization Mass Spectrometry. Anal. Chem. 2007, 79, 8301-8311.

40. Sakamoto, S.; Fujita, M.; Kim, K.; Yamaguchi, K. Characterization of Self-Assembling Nano-Sized Structures by Means of Coldspray Ionization Mass Spectrometry. Tetrahedron 2000, 56, 955-964.

41. Tsuda, A.; Nakamura, T.; Sakamoto, S.; Yamaguchi, K. Osuka, A. A Self-Assembled Porphyrin Box from Meso-Meso-Linked Bis[5-p-pyridyl15-(3,5-di-octyloxyphenyl)porphyrinato Zinc(II)]. Angew. Chem. Int. Ed. $2002,41,2817-2821$.

42. Sakamoto, S.; Yamaguchi, K. Hyperstranded DNA Architectures Observed by Cold-Spray Ionization Mass Spectrometry. Angew. Chem. Int. Ed. 2003, 42, 905-908.

43. Yamaguchi, K. Cold-Spray Ionization Mass Spectrometry: Principle and Applications. J. Mass Spectrom. 2003, 38, 473-490.

44. Nakatani, K.; Hagihara, S.; Sando, S.; Sakamoto, S.; Yamaguchi, K.; Maesawa, C.; Saito, I. Induction of a Remarkable Conformational Change in a Human Telomeric Sequence by the Binding of Naphthyridine Dimer: Inhibition of the Elongation of a Telomeric Repeat by Telomerase. J. Am. Chem. Soc. 2003, 125, 662-666.

45. Nishimura, S. I.; Nagahori, N.; Takaya, K.; Tachibana, Y.; Miura, N.; Monde, K. Direct Observation of Sugar-Protein, Sugar-Sugar, and Sugar-Water Complexes by Cold-Spray Ionization Time-of-Flight Mass Spectrometry. Angew. Chem. Int. Ed. 2005, 44, 571-575.

46. Nagao, Y.; Miyamoto, S.; Miyamoto, M.; Takeshige, H.; Hayashi, K.; Sano, S.; Shiro, M.; Yamaguchi, K.; Sei, Y. Highly Stereoselective Asymmetric Pummerer Reactions That Incorporate Intermolecular and Intramolecular Nonbonded S . . . O Interactions. J. Am. Chem. Soc. 2006, $128,9722-9729$
47. He, J.; Abliz, Z.; Zhang, R.; Liang, Y.; Ding, K. Direct On-Line Method To Monitor the Dynamic Structure of Noncovalent Titanium Complexes in Solution by Using Cold-Spray Ionization Time-of-Flight Mass Spectrometry. Anal. Chem. 2006, 78, 4737-4740.

48. Evansa, S. V.; Brayer, G. D. High-Resolution Study of the ThreeDimensional Structure of Horse Heart Metmyoglobin. J. Mol. Biol. 1990, 213, 885-897.

49. Fruman, D. A.; Burakoff, S. J.; Bierer, B. E. Immunophilins in Protein Folding and Immunosuppression. FASEB J. 1994, 8, 391-400.

50. Liu, J. FK506 and Cyclosporin, Molecular Probes for Studying Intracellular Signal Transduction. Immunol. Today 1993, 14, 290-295.

51. Galat, A. Peptidylproline cis-trans-Isomerases: Immunophilins. Eur. J. Biochem. 1993, 216, 689-707.

52. Goto, Y.; Hagihara, Y.; Hamada, D.; Hoshino, M.; Nishii, I. AcidInduced Unfolding and Refolding Transitions of Cytochrome c: A Three-State Mechanism in Water and Deuterium Oxide. Biochemistry 1993, 32, 11878-11885.

53. Konermann, L.; Douglas, D. J. Acid-Induced Unfolding of Cytochrome c at Different Methanol Concentrations: Electrospray Ionization Mass Spectrometry Specifically Monitors Changes in the Tertiary Structure. Biochemistry 1997, 36, 12296-12302.

54. Cech, N. B.; Enke, C. G. Practical Implication of Some Recent Studies in Electrospray Ionization Fundamentals. Mass Spectrom. Rev. 2001, 23, 368-389.

55. Kebarle, P.; Peschke, M. On the Mechanism by Which the Charged Droplets Produced by Electrospray Lead to Gas Phase Ions. Anal. Chim. Acta 2000, 406, 11-35.

56. Kattat, V.; Chit, B. T. Hydrogen/Deuterium Exchange Electrospray Ionization Mass Spectrometry: A Method for Probing Protein Conformational Changes in Solution. J. Am. Chem. Soc. 1993, 115, 6317-6321.

57. Pan, J.; Wilson, D. J.; Konermann, L. Pulsed Hydrogen Exchange and Electrospray Charge-State Distribution as Complementary Probes of Protein Structure in Kinetic Experiments: Implications for Ubiquitin Folding. Biochemistry 2005, 44, 8627-8633.

58. Hoerner, J. K.; Xiao, H.; Kaltashov, I. A. Structural and Dynamic Characteristics of a Partially Folded State of Ubiquitin Revealed by Hydrogen Exchange Mass Spectrometry. Biochemistry 2005, 44, 1128611294.

59. Konermann, L.; Rosell, F. I.; Mauk, A. G.; Douglas, D. J. Acid-Induced Unfolding of Cytochrome c at Different Methanol Concentrations: Electrospray Ionization Mass Spectrometry Specifically Monitors Changes in the Tertiary Structure. Biochemistry 1997, 36, 6448-6454.

60. Babu, K. R.; Douglas, D. J. Methanol-Induced Conformations of Myoglobin at pH 4.0. Biochemistry 2000, 39, 14702-14710.

61. Zhao, C.; Wood, T. D.; Bruckenstein, S. Shifts in Protein Charge State Distributions with Varying Redox Reagents in Nanoelectrospray Triple Quadrupole Mass Spectrometry. J. Am. Soc. Mass Spectrom. 2005, 16, 409-416. 